\title{
LUT
}

Lappeenranta

University of Technology

\section{Sustainability goal setting with a value-focused thinking approach}

\author{
Manninen Kaisa, Huiskonen Janne
}

This is a Final draft version of a publication

published by Palgrave Macmillan

in Sustainable Business Models

DOI: $10.1007 / 978-3-319-93275-0 \_4$

Copyright of the original publication: (c) The Author(s) 2019

Please cite the publication as follows:

Manninen, K. and Huiskonen, J. (2018). "Sustainability goal setting with a value-focused thinking approach". Book section, in Sustainable Business Models. Innovation, Implementation and

Success. Edit. Aagaard, A. Publisher, Palgrave Macmillan. DOI: 10.1007/978-3-319-93275-0_4 


\title{
Sustainability goal setting with a value-focused thinking approach
}

\author{
Kaisa Manninen ${ }^{1}$ and Janne Huiskonen ${ }^{1}$ \\ ${ }^{1}$ Industrial Engineering and Management, Lappeenranta University of Technology, Finland
}

Version: final draft post-refereeing. Please cite as: Manninen, K. and Huiskonen, J. (2018).

"Sustainability goal setting with a value-focused thinking approach". Book section, in Sustainable

Business Models. Innovation, Implementation and Success. Edit. Aagaard, A. Publisher, Palgrave

Macmillan.

\begin{abstract}
Firms are increasingly setting themselves business goals that are more and more sustainabilityoriented. It is, however, unclear what the rationale behind the sustainability-related decisions are: whether the improvement of sustainability is the fundamental purpose of the firm's business or whether sustainability is just an opportunity to improve some of the firm's competitive factors, such as reputation and image, i.e., a means to achieve economic success. We suggest that to be able to assess the consequences of sustainability-related decisions better, a factual basis is needed, and for that, sustainability science offers a proper perspective. Sustainability science helps decision makers to understand how the firm can contribute to a more transformational change with its sustainability objectives. An approach called value-focused thinking is helpful in clarifying the strategic goal-setting process and the role of sustainability goals in it, and in connecting values to firms' strategic decisionmaking. In addition, the values and objectives can be analyzed by applying the concepts of alternative objective functions for the firm in order to understand the relationship of profit and sustainability in the decision-making context. In this chapter, we present a Values-Driven Sustainability Management Framework, which combines the values of decision makers, the sustainability objectives of the firm, and a scientific perspective to sustainability to foster sustainable development. The framework can be utilized in making sustainability-related goal setting more transparent, so that the decisions are based on the values the firm wishes to follow. The approach supports the early phase of sustainable business model innovation and facilitates the developing of value propositions that are in line with the fundamental values of the firm.
\end{abstract}




\section{Introduction}

Today, when sustainability is proclaimed as the next frontier in innovation, almost all organizations accept the concept (Silvestri and Gulati, 2015). Firms are concerned with sustainability issues and want to contribute to it with their actions (Palmer and Flanagan, 2016). Organizational change towards sustainability can be approached from an organizational or institutional level of analysis. In the former, the leaders of the organization are important players in the journey towards sustainability. The institutional perspective is very different and considers the contextual circumstances that enable, push, or inhibit organizations from moving from one state to another. The role of managers in the change process are seen as secondary. (Greenwood et al., 2015.) In this chapter we concentrate on the organizational perspective, because one viewpoint is that sustainability is often not in the core of an organization, but apart from the strategy. Organizations that truly embrace sustainability, should move sustainability to their core. (Silvestri and Gulati, 2015.) Thus, sustainability initiatives and claims should be aligned with the organization's identity (Glynn et al., 2015). The organizational identity is influenced strongly by the values of the owners and top managers who together form the basis for corporate responsibility (Bansal and Song, 2017, Kaldschmidt, 2011) and have an effect on how the organization makes sustainability decisions.

Maximizing profit has been the predominant logic in doing business. However, sustainability has increased its importance, but it is difficult to analyze to what extent sustainability is only a means to achieve profit, to what extent they have equal weight, and in which cases sustainability may have even greater importance than profit. Therefore, it is important to capture the rationale in sustainability management practices (Schaltegger and Hörisch, 2017). Understanding the fundamental objectives of the firm can help to provide purpose and meaning for the business and thus clarify the question of rationale.

We approach the problem of profit versus sustainability from ethical and scientific perspectives of sustainability. The aim is firstly to understand how the values of decision makers affect the sustainability objectives of the firm, and secondly how sustainability science can assist decision makers by providing a factual basis of sustainability in decision-making situations, and thus contribute to sustainability management.

To understand the values of decision makers and their impact, we propose two approaches. The Value-Focused Thinking (VFT) approach (Alencar et al., 2017, Keeney, 1992, 1994, 1996) is used to examine and reveal the sustainability objectives of the firm and to understand the values of decision makers behind the objectives. In addition, the values and objectives are analyzed by applying the concepts of the alternative objective functions for the firm (Lankoski and Smith, 2017) in order to understand the relationship of profit and sustainability in the decision-making context.

We suggest that to assess the consequences of sustainability-related decisions better, a factual basis is needed, and sustainability science offers a proper perspective for that. Sustainability science helps decision makers to understand how the firm can contribute to a more transformational change with its sustainability objectives. Decision makers can then reassess their objectives and purpose in doing business, and decide whether the objectives truly represent their firm's identity, i.e. what the firm wants to be and what kind of external image it gives to its stakeholders (Silvestri and Gulati, 2015). Our study provides a framework to support the sustainability management of a company by combining the values of decision makers, the sustainability objectives of the firm and a scientific perspective of sustainability to foster sustainable development. 


\section{Understanding the purpose of doing business}

Organizations need a multidimensional view of performance (Bansal and Song, 2017), and in many companies the objective of business is already something different than only profit (Lankoski and Smith, 2017). For example, according to the institutional logic, great companies create frameworks that use societal value and human values as decision-making criteria instead of extracting more economic value. These companies believe that corporations have a purpose, and they meet stakeholders' needs in many ways. However, all companies need capital to carry out business activities and sustain themselves. Profit is not the sole end, but a way to ensure that returns will continue (Kanter, 2011). Sustainable organizations must make profit to exist, but they do not just exist to make profit (Stubbs and Cocklin, 2008). Social welfare is an implicit objective and a firm is defined around its purpose and values (Kanter, 2011, Lankoski and Smith, 2017). The purpose of a sustainable company can be defined as a concrete goal or objective that reaches beyond profit maximization, i.e. environmental and social outcomes (Henderson and Van den Steen, 2015, Stubbs and Cocklin, 2008). At the same time profit is a "means" to achieve sustainable outcomes (Stubbs and Cocklin, 2008). A firm does not have to have only one objective or purpose for doing business, but it can contain e.g. both profit and social welfare. In the situation of many purposes, the relationship between different objective variables has to be specified clearly (Lankoski and Smith, 2017).

Lankoski and Smith (2017) define different relationship types between profit and social welfare (Table 1). An alternative objective function is an equation specifying which output the firm aims to maximize or minimize, with which variables as inputs, and under which constraints. The relationship types are based on three analytical dimensions: 1 ) whether the two variables are considered as process characteristics or end objectives, 2) whether preferences between the two variables are lexicographic or compensating, and 3) whether the relationship between the two variables is mutually supportive or mutually conflicting. The first two dimensions are decision issues, meaning that managers or owners can decide how they want to conceive the relationship between the two variables in their firm. The third dimension is, by contrast, an empirical question, which determines whether certain approaches to combining profit and social welfare are in fact possible in the real world. Ten different alternative objective functions for firms can be identified on the basis of the different relationships (Table 1). One of the functions excludes and nine include social welfare, meaning that social welfare can be 1 ) entirely absent from the objective function, 2 ) a process characteristic, 3 ) one of the end objectives, 4) the only end objective, adjusted by profit as a process characteristic, and 5) the only variable in the objective function.

Table 1. Relationships between the variables of profit and social welfare (Lankoski and Smith, 2017).

\begin{tabular}{ll}
\hline Relationships between the variables of profit and social welfare \\
\hline None & Only one variable is maximized and there is no place for the other variable \\
\hline Instrumental & $\begin{array}{l}\text { One variable (the instrumental variable) is a means for achieving the other variable } \\
\text { (the end objective) }\end{array}$ \\
\hline Constrained & $\begin{array}{l}\text { One variable (the objective) is maximized so that the value of the other variable } \\
\text { (the constrained) stays within a preset range }\end{array}$ \\
\hline Complementary & $\begin{array}{l}\text { Both variables are mutually supportive end objectives. Both variables may be } \\
\text { equally regarded as end objectives at the same time, and both may be maximized } \\
\text { at the same time. }\end{array}$ \\
\hline Hierarchical & $\begin{array}{l}\text { One variable has priority over the other, as in lexicographic ordering. The more } \\
\text { important objective is satisfied first, after which the less important objective is } \\
\text { satisfied to the extent possible without affecting the outcome of the first objective. }\end{array}$ \\
\hline
\end{tabular}



priority varies from one decision-making situation to another according to preset criteria.

The alternative objective functions provide a basis for considering organizational purpose also from the sustainability point of view. The alternative objective functions extend the discussion of different logics to do business and provides a framework to aid organizational change towards sustainability. The term sustainability is defined in closer detail below, but in this context, it includes the economic, environmental and social perspectives of business in general. We apply the alternative objective functions to explore different logics to do business from the perspective of profit and sustainability (Figure 1). In our viewpoint, the conventional financial logic represents the extreme of the relationship type "None". Sustainability logic has received increased attention, but in many cases it still appears as an instrumental logic to do business, where environmental and social actions are means to achieve profit (Gao and Bansal, 2013). The integrated logic presented by Gao and Bansal (2013) is close to the relationship type "Complementary" presented by Lankoski and Smith (2017). The Environmentally Dominant Logic by Montabon et al. (2016) is an opposite of financial logic, and represents a situation where priority is given to the environment, then to the society, and last to profit. In its extreme form, environmental and social welfare are maximized and there is no place for profit in it. However, as Lankoski and Smith (2017) state, this does not prevent a well-managed firm from making profit, but profit is the result rather than the driver in the process of value creation. Therefore, we see that when it is not the case of social enterprises but companies doing business, the company needs some capital to carry out business activities and sustain themselves (Kanter, 2011).

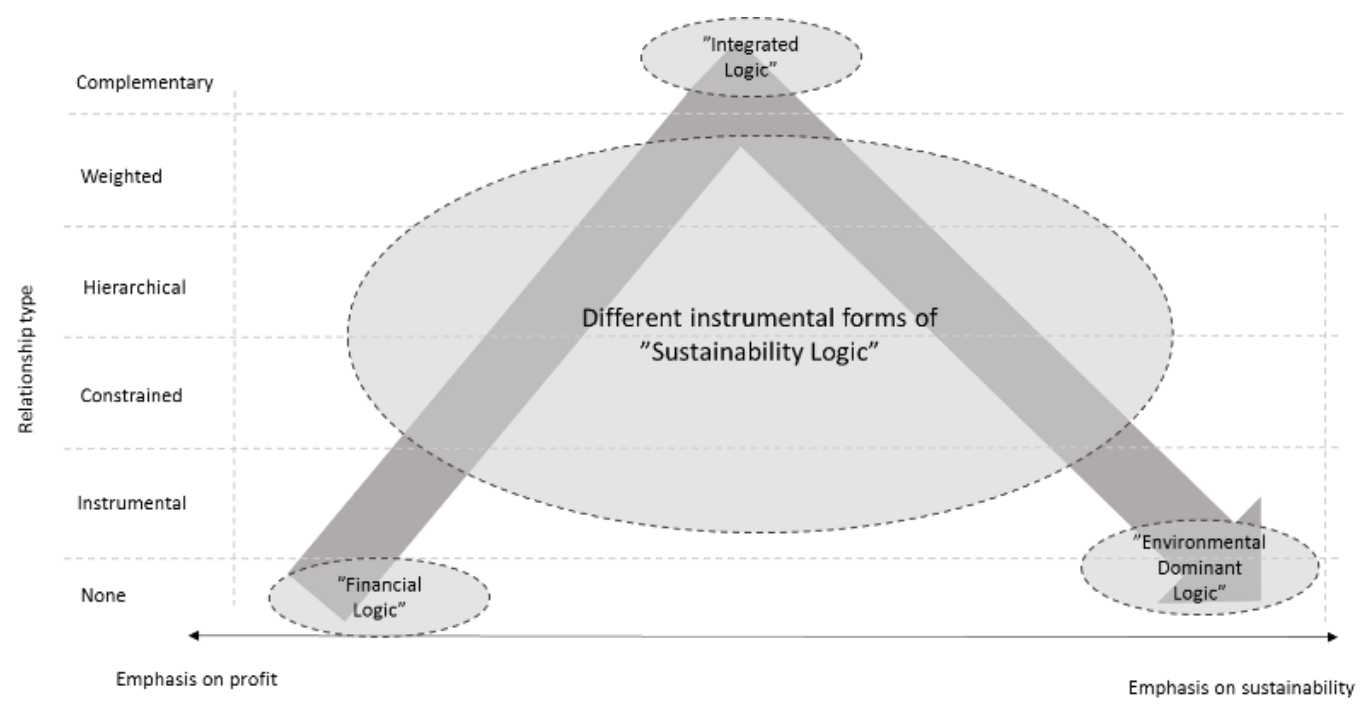

Figure 1. The relationship types of profit and sustainability (reproduced from Lankoski and Smith, 2017) combined with the "Financial Logic", "Integrated Logic" (Gao and Bansal, 2013), "Environmental Dominant Logic" (Montabon et al. 2016), and "Sustainability Logic (e.g. Gao and Bansal 2013; Greenwood et al. 2015)

One of the challenges in building truly sustainable organizations is that although firms' strategies increasingly integrate sustainability (Palmer and Flanagan, 2016), and different logics to do business can be identified (Figure 1), it often requires a significant shift in the identity of the firm, as well as in its core structure and processes (Henderson et al., 2015). The organizational identity defines "what the organization is" and "what it stands for" (Silvestri and Gulati, 2015). By understanding the different alternative purposes for business, the company can reflect them towards their identity. According to Lankoski and Smith (2017), managers or owners can decide how they regard the 
relationship between profit and sustainability in their firm. The personal values of managers influence their strategic decisions (Kaldschmidt, 2011), and thus sustainability-related decisions are likely affected by the decision makers' values. However, sustainability is a complex issue, and decision makers have often difficulties to see the effects of their decisions in a larger, systemic-level context. The scientific perspective can offer a factual perspective to solve this problem. However, decision makers still have to clarify to what extent they base their decisions on values and to what extent on facts.

\section{Combining values and scientific viewpoints in sustainability decision making}

Managerial values play an important role in all decisions and especially in strategic decision making, because they are embedded in the organizational values. Therefore, sustainability-supporting values of leaders and managers are a key to making strategic decisions that support the successful balance of economic, environmental and social goals. (Kaldschmidt, 2011)

Values form the basis of the ethical standpoint of the firm's decision makers, and therefore business ethics can be understood to be the ideas about conduct that are generally accepted among the members of a group that operates within a company. In other words, values guide individual employees' judgement and action in situations that are not governed by laws or other institutionalized elements. (Pearce, 2013.) From the research perspective, business ethics evaluates humanistic values in management and gives meanings to it. However, factual data from science is needed to discover the causes and effects of decisions. Therefore, it is useful to understand how ethics and science are manifested in corporate sustainability discussion. On the basis of historical roots, ethics can be linked to corporate responsibility, whereas the background of sustainability is in natural sciences. (Bansal and Song, 2017.) However, in many companies corporate responsibility and sustainability are synonyms (Bansal and Song, 2017, Markman et al., 2016). The separation of the concepts clarifies the discussion, when considering and making decisions about sustainability management.

Applying perspectives from both corporate responsibility and sustainability increases understanding of how to set better and effective sustainability objectives. Firstly, corporate responsibility represents the ethical standpoint of the company. Corporate responsibility combines the values and beliefs of the decision makers at the individual level, but also presents why and how the company commits to sustainability at the organizational level. Secondly, sustainability-related decisions can be justified by factual data from the scientific perspective of sustainability. (Bansal and Song, 2017.) Finally, sustainability management operationalizes corporate responsibility and sustainability science at the organizational level by including formulation, implementation, and evaluation of environmental and socioeconomic sustainability-related decisions and actions (Starik and Kanashiro, 2013) (Figure 2). 


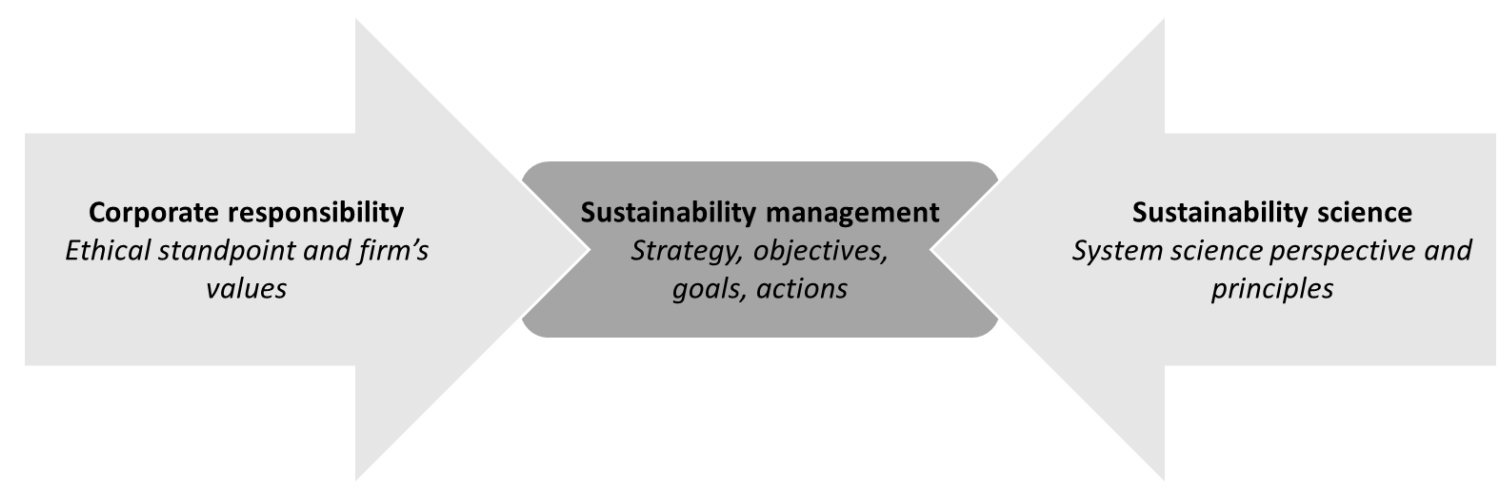

Figure 2. Corporate responsibility and sustainability science perspectives to support sustainability management at the organizational level.

\subsection{Values for sustainability decisions}

The values of decision makers are formed in part by the organization they work for. By exploring decision makers' values, we can recognize how the organization understands sustainability and what is its orientation towards it; whether sustainability is at the periphery or at the core of the organization's identity (Silvestri and Gulati, 2015).

According to den Ouden (2012), from the psychological perspective, values define what people strive for (human values) and how they influence their behavior (motivational values). At the organizational level, the purpose and objectives are based on the core values of the firm, and provide motivation for its management and employees to contribute to the creation of value (den Ouden, 2012). Kaldschmidt (2011) studied in her dissertation the intersection of personal values, corporate sustainability, and how leaders' personal values influence the strategy process and its outcomes in terms of the formulation of competitive sustainability strategies. She utilized Schwartz' theory of basic human values, which is based on the idea that values guide individuals and are grounded in what they see as desirable. Fundamentally, they have different motivational aspects, as in the definition by den Ouden (2012). Kaldschmidt (2011) presents five main features of Schwartz' theory that all conceptions of values have (Schwartz, 2006, Schwartz and Bilsky, 1987, Schwartz, 1992 in Kaldschmidt (2011)):

1) Values are beliefs. These beliefs are tied to emotion and not to objective ideas.

2) Values are a motivational construct. That is, they refer to desirable goals that are worth striving for.

3) Values transcend specific situations. The abstract nature of values distinguishes them from norms and attitudes, which refer to more specific actions, objects or situations.

4) Values guide selection or evaluation (of actions, policies, people, and events). This way, values can be understood as standards or criteria.

5) Values are ordered by relative importance to one another. Individuals hold values in ordered systems that include priorities. The hierarchical nature of values also differentiates them from attitudes and norms.

Kaldschmidt (2011) studied which personal values of leaders need to be prioritized in order to make strategic decisions that support the sustainable development and performance of a firm. She found a connection between the certain personal values profiles of leaders and the sustainability strategy of a firm. She also stated that for sustainable business practices to be reality and not just greenwashing, more is needed than just putting up a values statement that includes social and environmental responsibility. 
In-depth understanding of the decision makers' sustainability-related values can provide a useful insight into the core values of an organization and its purpose to do business. Referring to the main features of Schwartz' theory of basic human values, sustainability -related values could be interpreted as guiding principles for decision makers towards desirable, trans-situational economic, environmental and social goals, varying in importance (Schwartz, 2007). Although we concentrate on the understanding of human values, it is notable that the sustainability value concept can be approached also from sociological and ecological perspectives. Then it is not a matter of human values, but seeing that the society and nature are a value in themselves (den Ouden, 2012). For that perspective, i.e. to understand the absolute value of the society and nature, science can offer factual data to support decision making (Bansal and Song, 2017).

\subsection{Scientific viewpoints to sustainability}

Earlier studies have brought out concern about the effects of sustainability management. Although companies are willing to impact sustainability issues, and sustainability actions are taken in several companies, ecological analyses indicate worsening or even alarming conditions (Dyllick and Muff, 2016, O'Neill and McElroy, 2017, Whiteman et al., 2013). One reason for this is that companies' sustainability goals and the progress towards them are commonly assessed on the basis of comparisons 1) relative to a baseline year (e.g., the last reporting period), 2) relative to the current best practice (e.g., best performers in an industry), or 3) relative to the company's own targets (e.g., to reduce $\mathrm{CO}_{2}$ emissions by $20 \%$ by 2020). These kinds of benchmarks can lead to situations where incremental, and in absolute terms even ineffective improvements are seen as progress towards sustainability. (Kurucz et al., 2017.) In addition, to use these kinds of benchmarks as a measure of sustainability progress, setting goals only based on e.g. the level of best practice of the industry, may lead to ineffective actions, and in the worst case, the goals are not linked to the overall strategic objectives of the company at all. Another reason for ineffective results of sustainability management is that the sustainability strategy is not linked to macro-ecological processes and boundary conditions. In other words, the scientific viewpoint of sustainability is ignored (Whiteman et al., 2013).

The Triple Bottom Line (TBL) has been a dominant concept to describe sustainability (Montabon et al., 2016). It incorporates three performance dimensions: social, environmental and financial, and represents thus in an optimal situation the ideology of "Integrated Logic" (Gao and Bansal, 2013) to do business (see Section 2). However, in reality, social and environmental aspects are often instruments to improve economic performance (Montabon et al., 2016), representing the left side of Figure 1, where the emphasis is on profit. This results from a technocentric (a.k.a. anthropocentric (Purser et al., 1995)) worldview about sustainability, which requires increases in production and consumption, economic growth, and valuation and utilization of natural resources. In addition, the technocentric approach views man's role as one of control over nature. (Landrum and Ohsowski, 2017.)

The concern for a technocentric bias in the field of organizational science concerning social issues in management or relations between business and the natural environment was already highlighted in the 1990s. It was stated that "if researchers and managers are to move toward an "ecocentric" paradigm, they need more than a popular understanding of ecology. Indeed, there is a need to clearly differentiate anthropocentric from ecocentric approaches to environmental issues" (Purser et al., 1995, p.1055). The same criticism was raised twenty years later when Starik and Kanshiro (2013, p. 9) argued that "...one or more new theories of sustainability management may be needed in the management literature...most other organization/management theories that have been used in sustainability research do not either explicitly or implicitly recognize the obvious (or near-obvious) 
fact that all human organizations are embedded within the natural environment, and that, all of those which have human managers and other employees, also contain the natural environment inside of their respective biophysical bodies".

Recent research supports the ecocentric worldview in sustainability (Whiteman et al., 2013), which recognizes that economic growth is bounded by environmental limits, natural resources need to be preserved to support life, and all activity must remain within ecological limits (Landrum and Ohsowski, 2017). This is a systemic perspective towards sustainability, including natural and social systems. The systemic approach makes sustainability a complex issue to understand at the organizational level. Therefore, sustainability science can provide material for micro-level organizational implementation of sustainability, as individual companies are a part of larger social systems (Bansal and Song, 2017).

When discussing sustainability, it is almost necessary to bring out the term sustainable development. Probably the best known description for the term is the definition by the Brundtland Commission: "Sustainable development is development that meets the needs of the present without compromising the ability of future generations to meet their own need" (Broman et al., 2012, p. 21). Shortly, it means the transition from the current, unsustainable society to a sustainable society (Broman et al., 2012). The report of the Commission took a systemic perspective, arguing that the world's complex challenges could be solved only by systematic collective endeavors, and the collapse of natural systems would erode the sustainability of organizational systems, as all physical resources are ultimately drawn from the earth. Furthermore, poor social conditions could catalyze organizational dissent. Therefore, the systems scholars assumed that corporate actions were inherently connected to the social and natural systems. (Bansal and Song, 2017.)

\subsection{Value profiles for clarifying a company's sustainability strategy}

Significant changes are needed in the transition towards a sustainable society in order to realize sustainable development (Broman et al., 2012). In the two sections above we discussed firstly values of decision makers, which form the base for corporate responsibility and how the firm commits to sustainability, and secondly the scientific perspective of sustainability, which can support decision makers to take a more systemic approach in sustainability-related decision making.

When there is a strong cohesion of sustainability -oriented values among decision makers, strategic and operational sustainability-related decisions will be more likely made consensually (Kaldschmidt, 2011). Further, it could be interpreted that if the values of decision makers are consensually aligned with the scientific perspective of sustainability complying with sustainability principles, an effective sustainability strategy will be likely to be implemented. Therefore, in order to truly foster sustainable development, the values of decision makers and the scientific perspectives of sustainability in sustainability management have to be combined.

The levels of management can be divided into three parts: 1) normative management, which defines the basic management philosophy and the company's identity, 2) strategic management, which defines long-term strategic goals, and 3) operational management, which defines how the organization can reach its goals (Baumgartner, 2014). When applying the management levels to sustainability management, our approach provides input mainly to the normative and strategic management levels (Figure 3). 


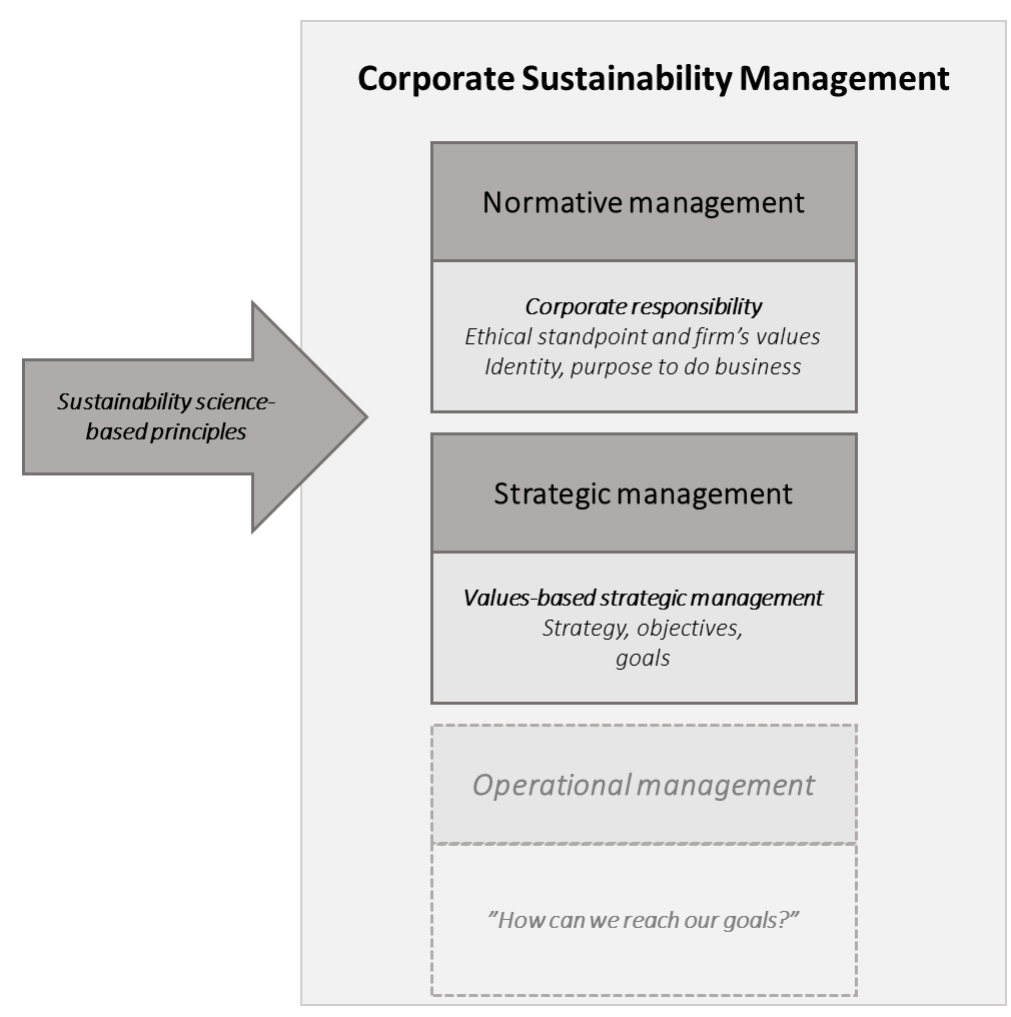

Figure 3. Sustainability management levels (based on (Baumgartner, 2014) supported by sustainability science-based principles.

We see consistency between the organizational purposes to do business (based on the relationship types by Lankoski and Smith (2017)) and the viewpoints on sustainability (Figure 4). We express this consistency as alternative value profiles, representing the organizational purpose to create environmental, social and economic output in different relationships.. The points along the arrow are manifestations of different value profiles, where the beginning of the arrow (left corner) represents a profit-dominant profile and the right head of the arrow a sustainability-dominant profile. The top of the arrow represents an integrated profile. Our interpretation is that when a company is moving from the profit-dominant profile towards the sustainability-dominant profile (from left to right), the instrumental role of the environmental and social perspectives of sustainability changes to having a role of absolute value. In other words, the purpose to do business changes from a financial logic to a more sustainability-dominant logic and an ecocentric worldview to do business. Alignment of organizational values with (the requirements of) the respective value profile is important if a company plans to change its position in the value continuum. In accordance with our earlier assumption, in order to reach the right corner, the values of decision makers should be aligned with the ecocentric worldview of sustainability. However, the philosophy of the ecocentric worldview has to be operationalized in order to be able to carry out business in accordance with ecocentric sustainability principles. The operationalization of the ecocentric worldview is discussed in Section 4.2 . 


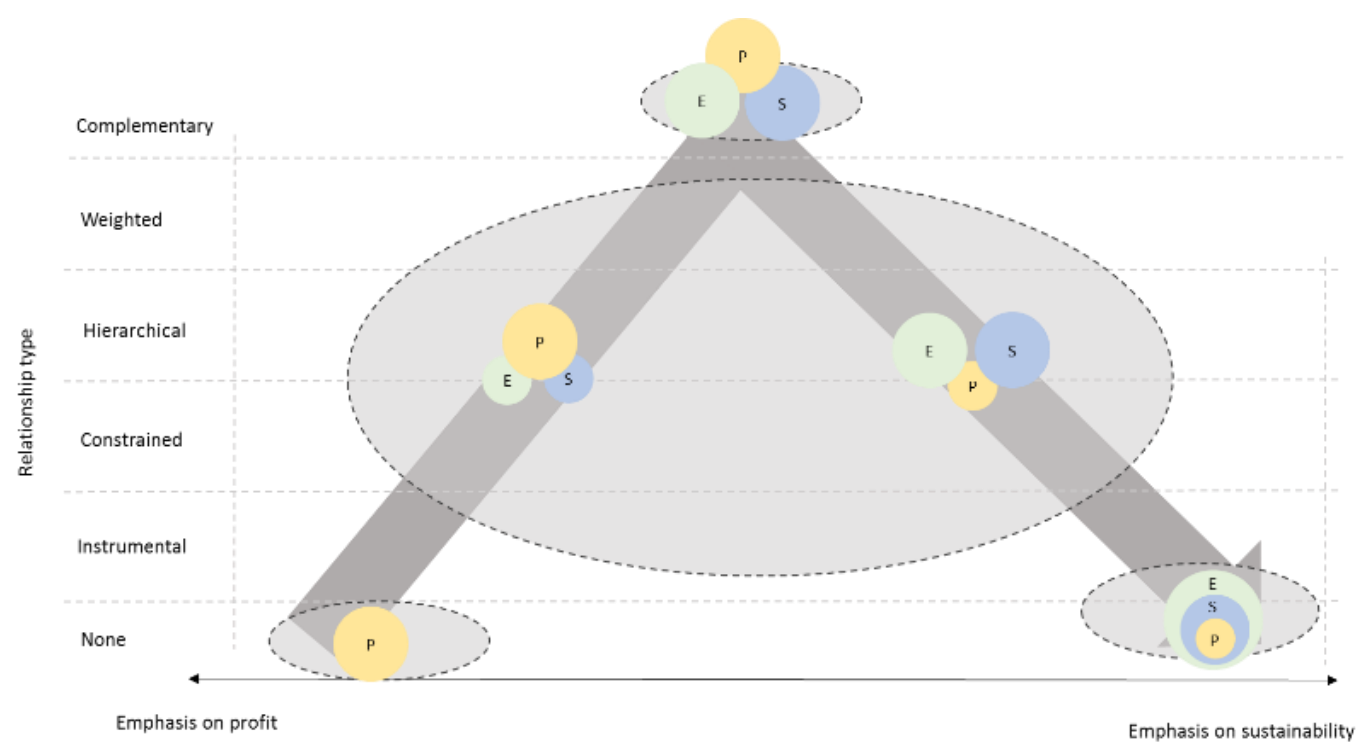

Figure 4. Possible value profiles of a company (based on the range of alternative objective functions by Lankoski and Smith, 2017)).

By positioning itself to some point along the arrow, the firm can identify who they are and who they want to be. In other words, the firm can consider its purpose beyond profits (Henderson and Van den Steen, 2015). This is done at the normative management level, and it defines the basis for strategic management. Strategic management is a process of planning, implementing and evaluating company-wide decision making, enabling an organization to achieve its long-term objectives (Baumgartner, 2014). In other words, normative management clarifies the strategic sustainability goal setting and makes sustainability-related goal setting more transparent, so that the decisions are based on the values the firm wants to follow. In addition, this approach supports the operational management level, where the sustainability strategy is implemented (Baumgartner, 2014). Normative management provides a basis for the early phases of sustainable business model innovation, and facilitates developing value propositions that are in line with the fundamental values of the firm.

\section{Framework of Values-Driven Sustainability Management}

In the sections above, we stated that effective sustainability management requires combining the ethical and scientific perspectives of sustainability. The values of decision makers are in an important role in strategic sustainability decision making. In order to foster sustainable development effectively, the values of the decision makers have to be aligned with the scientific principles of sustainability. In practice, this will help the decision makers to set concrete sustainability objectives and goals and put them into action.

In order to help decision makers to consider their values and combine the scientific perspective of sustainability to them, we present a framework of Values-Driven Sustainability Management (VDSM) (Figure 5). The framework includes existing approaches that can be used as tools to combine ethical and scientific perspectives in practice. We have modified the approaches in order to create a comprehensive framework for VDSM. The alternative objective functions approach used in phase 2 was described in section 2 above, as it introduces the discussion of a firm's purpose to do business. The applied approaches used in phases 1 and 3 are described in sections 4.1 (Value-Focused Thinking) and 4.2 (Future-Fit Business Benchmark), as they are more concrete methods to be utilized. Section 4.3 describes the fourth phase of the framework. 


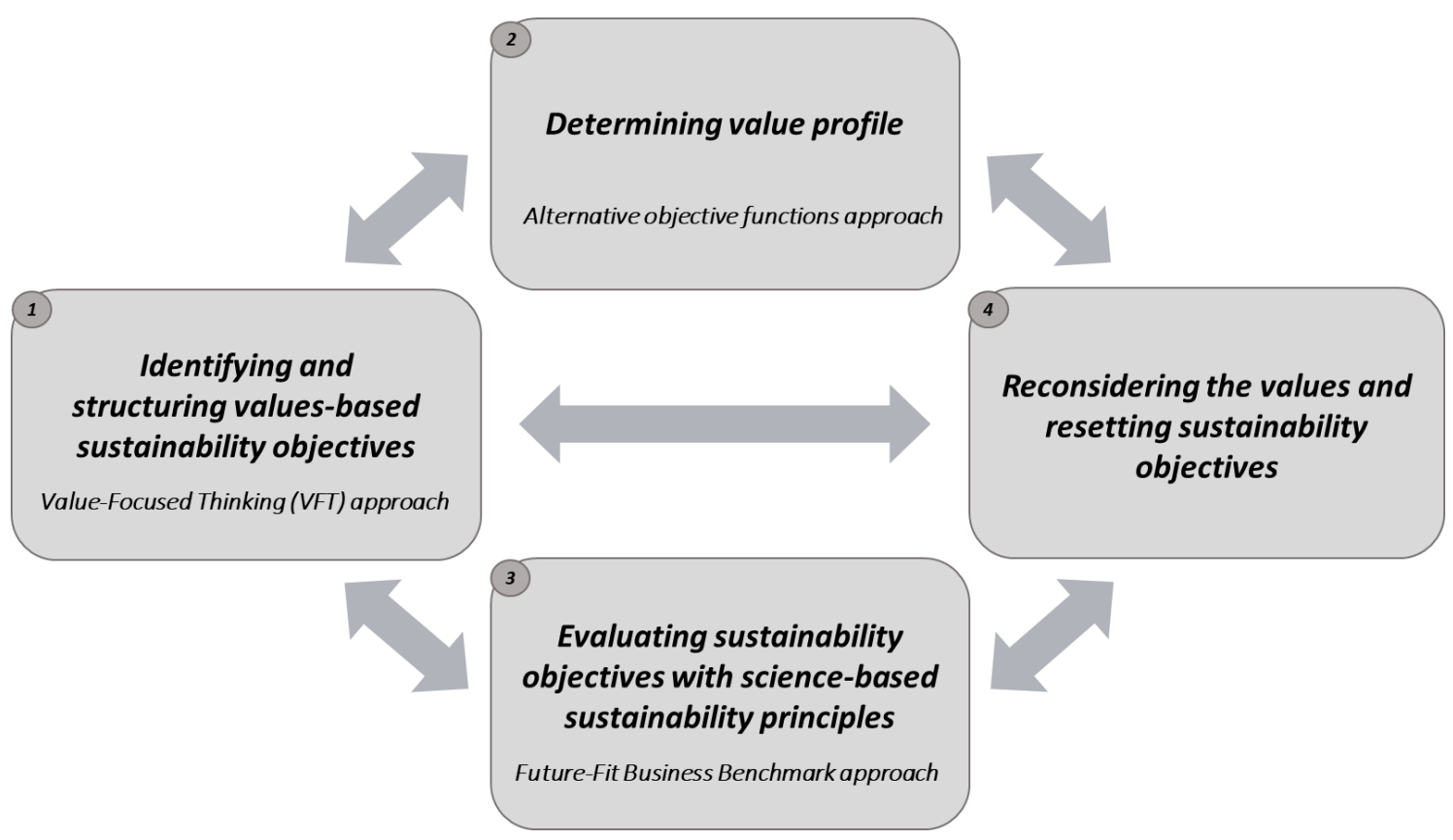

Figure 5. Framework for effective Values-Driven Sustainability Management.

The framework consists of four iterative phases and specific approaches. In the first phase, the Value-Focused Thinking (VFT) approach (Chapter 4.1.) is utilized to identify and structure valuesbased sustainability objectives. The starting point is the firm's sustainability objectives in a certain decision context. The aim is to structure the means-ends network of the objectives, where the ends represent the fundamental objectives, and the means help to achieve the ends. With the help of the means-end network, the fundamental objectives of the firm can be identified, and it can be recognized how the sustainability objectives are positioned in this network. The objectives are grouped depending on how they represent the environmental, social or economic dimensions of sustainability. This phase helps to clarify the question of whether sustainability is the fundamental purpose of the firm's business or whether sustainability is just an opportunity to improve some of the firm's competitive factors.

In the second phase, the alternative objective functions approach is used to identify the value profile (Figure 4 and Section 2) of the company. The objective network, structured in the first phase, is reflected against the relationship types of profit and sustainability, and it is analyzed what the emphasis of the objectives is from the profit-sustainability perspectives. With the help of this phase, the management philosophy can be determined, and it can be identified how well it represents the ecocentric worldview.

In the third phase, the scientific perspective of sustainability is involved. We suggest using the Future-Fit Business Benchmark (Section 4.2), which relies on the ecocentric worldview and uses science-based environmental and social system conditions as a basis to define the business principles for sustainable business (Kurucz et al., 2017). The aim of this phase is to present the scientific perspective for sustainable business to decision makers, so that they can reassess their values and purpose to do business against this perspective.

In the fourth phase, the decision makers can reconsider their values and possibly restructure their own sustainability objectives, based on the analysis done in the earlier phases (Section 4.3). 


\subsection{Value-Focused Thinking approach for identifying and structuring objectives}

In Section 3.1 we stated that decision makers' values are formed in part by the organization they work for and on the basis of the company's identity. Further, the company's identity affects how the company is oriented towards sustainability-related decisions. Decision making is often based on choices between alternatives, and the decision maker concentrates first on the alternatives to solve a problem or achieve a goal, and after that addresses the objectives or criteria to evaluate the alternatives. This kind of a decision making approach is called alternative-focused thinking (Keeney, 1992, 1996) However, the time and effort spent in relation to decision making is used best when thought is given to values. This will generate viable alternatives that are in accordance with the values of the decision makers involved. The VFT methodology seems to be advantageous compared to other traditional methods applied in decision making in the context of sustainability. (Alencar et al., 2017.) It differs from the alternative-focused paradigm by the following features (Keeney, 1992, Keeney, 1996):

- The values are made explicit by identifying and structuring the values appropriate for the decision situation qualitatively.

- The articulation of values in decision situations comes before other activities.

- The articulated values are used explicitly to create alternatives and to identify decision opportunities.

We propose that applying the first two phases of VFT in the sustainability-related decision situation (Figure 6) helps to examine and reveal the sustainability objectives of the firm and to understand the values of the decision makers behind the objectives. An objective is a statement of something that one desires to achieve, and it is characterized by three features: a decision context, an object, and a direction to preference. A fundamental objective characterizes an essential reason for interest in the decision context. The means objective is of interest in the decision context because of its implications for the degree to which another (more fundamental) objective can be achieved. (Keeney, 1992)

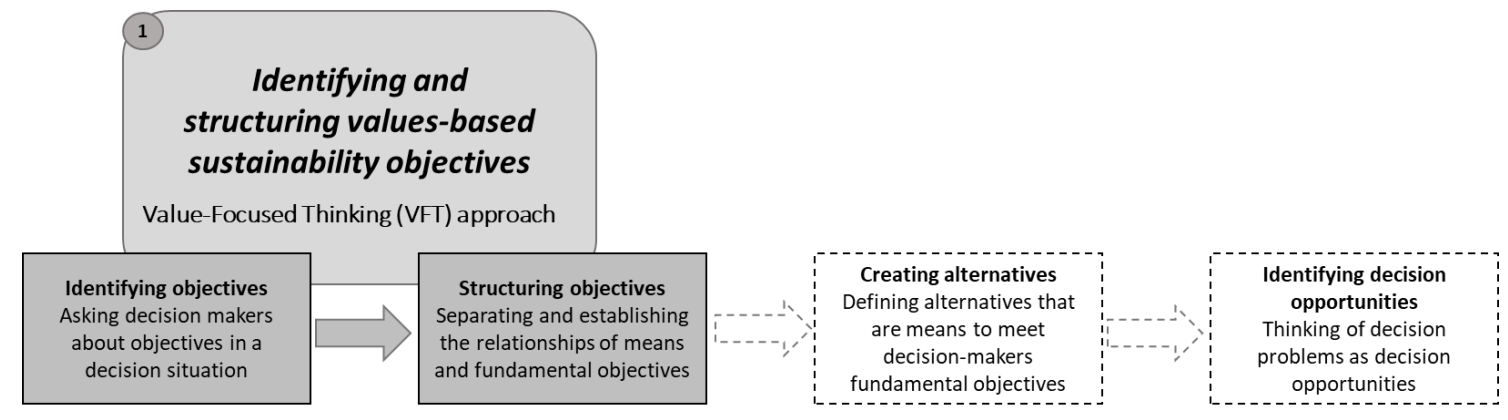

Figure 6. Connection of the Value-Focused Thinking (VFT) approach (Keeney, 1992, 1996) and the Values-Driven Sustainability Management Framework. The values of decision makers are identified and structured based on the techniques of the VFT. The phases of the VFT presented with dotted lines are excluded.

Sustainability objectives can vary depending on the decision context, but a company might also have sets of broader and general strategic sustainability objectives which guide the decision making. However, the first aim is to define the fundamental sustainability objectives in a certain decision context by asking for example what the decision maker wants to achieve in this decision context. At this stage, the objectives are not prioritized. The outcome is a list of all kinds of sustainability objectives. The next step is to structure the list and convert possible alternatives, constraints and criteria into objectives, and after that to separate the means and fundamental objectives and establish their relationships by examining the reasons for each. This step involves linking objectives 
through means-ends relationships and specifying fundamental objectives. Separating ends objectives from specific means objectives should lead to at least one fundamental sustainability objective in a given decision situation. (Keeney, 1996.) After the structuring phase, the means-ends network and the identified fundamental objectives can be utilized in the next phases of the framework.

Alencar et al. (2017) utilized the VFT approach to study the implementing of sustainability in a built environment. They structured objectives based on the values of the actors involved in civil construction. The aim was to provide actions that can be implemented during the design and construction phases and that may bring positive impacts to a sustainable building. This example shows that VFT can be applied successfully in the sustainability context. Therefore, we state that the VFT approach deepens the understanding of sustainability objectives set by decision makers. Sustainability objectives are linked to the values of decision makers, and further decisions come thus closer to the decision makers. The approach can also reveal new perspectives and change the attitudes of decision makers towards sustainability.

\subsection{Future-Fit Business Benchmark for evaluating objectives}

The international discussion about sustainable development started primarily by the Brundtland Commission's definition of sustainable development, and after that numerous definitions, frameworks, models, and initiatives have been developed to help make our societies more sustainable (Baumgartner, 2011). The Sustainable Development Goals (SDGs) provide strong guidance in terms of the impacts and outcomes that companies and other stakeholders should strive to deliver. Companies want to focus more on impacts with their sustainability goals, and SDGs provide both structure and ambition for companies to consider their goal setting (O'Neill and McElroy, 2017). However, to avoid incremental and ineffective improvements in sustainability and to motivate for real change, companies need a reference to a desired future state, which they can use as a benchmark to assess their sustainability progress (Kurucz et al., 2017).

There are several approaches aiming at operationalizing the idea and concepts of sustainable development. The approaches can be divided for example to strategic planning processes and approaches offering more concrete goals. The Framework for Strategic Sustainable Development (FSSD) is an example of a strategic planning process framework. In addition of the process framework, it contains principles that define sustainability (Broman and Robèrt, 2017). The contextbased goals offer more concrete goals aiming at allocating specific science- and/or ethics-based thresholds for companies (Bertels and Dobson, 2017, O'Neill and McElroy, 2017). An example of context-based goals is the Science-Based Targets approach, in which a company can adopt a target to reduce greenhouse gas emissions, which is in line with the level of decarbonization required to keep the global temperature increase below 2 degrees Celsius compared to pre-industrial temperatures (Science Based Targets, 2018). Another example of more concrete goals is the FutureFit Business Benchmark (FFBB), which is a science-based, co-created, and openly available framework intended to introduce a new generation of sustainability metrics (Future-Fit Foundation, 2017). Compared to the context-based goals, the FFBB defines the minimum acceptable level of environmental and social performance, which all organizations should strive at. The philosophy of the FFBB is that we must change the way we do business, and only then will we be able to achieve the SDGs (Future-Fit Foundation, 2017, Kurucz et al., 2017).

We propose applying the FFBB to provide a factual scientific perspective for VDSM (phase 3 in Figure 5). To our knowledge, the FFBB presents the most comprehensive attempt aiming at operationalizing science-based environmental and social system conditions to the organizational 
level. The FFBB builds on the strategic sustainability paradigm that highlights the nested dependencies of nature, society, and economy, i.e. the ecocentric worldview. Shortly, the FFBB is a framework for performance assessment, including goals describing what a truly sustainable organization would look like, i.e. what an assessment of such a business would reveal in the best case (Kurucz et al., 2017). Reflecting on Figure 4, the FFBB represents the sustainability dominant logic to us.

The FFBB is based on sustainability principles of FSSD (also called system conditions), which offer clear guidance to what to aim for by defining what must not happen. From the business perspective, the system conditions offer a solid, science-based foundation for identifying what every company must do, as well as what any company may do beyond that (Broman and Robèrt, 2017, Future-Fit Business Benchmark, 2017, Kurucz et al., 2017) The system conditions are based on studies of ecological and social systems and dialogues with natural and social scientists (Broman and Robèrt, 2017). In the FFBB, every business is defined to be just one actor in a complex and dynamic value web, influencing and influenced by a wide range of other social systems. The value web is segmented into suppliers, operations, products, and the society. The value web serves as the basis for determining the extent to which a company should be held responsible for system condition breaches, and the degree to which a company may seek to have a positive impact. The company is responsibly and wholly accountable for impacts within its direct control, but also from the systems perspective mutually accountable for certain impacts out of its direct control. (Future-Fit Business Benchmark, 2017.)

In theory, every company could set sustainability goals based on the system conditions, but in practice, only most progressive companies are likely to invest in the effort required to find out how to do this. In addition, without clear guidance to what the destination is, companies would frame their ambitions and assess their progress in completely different ways. This can lead to incremental and even ineffective improvements in sustainability, as mentioned in section 3.2. Therefore, the FFBB provides 23 Break-Even Goals (Table 2), which are formulated so that they give business leaders a clear destination to aim for. The goals are grouped in four areas: fostering wellbeing, respecting nature, optimizing resources and strengthening the society. The goals are defined so that:

- Each goal is expressed as a single sentence, whose meaning can be grasped by business leaders, investors and other key stakeholders without lengthy explanations.

- Each goal represents the minimum level of performance to aim for in one part of the value web (e.g. products, operations) and relates to one issue (e.g. wages, waste)

- All goals together identify the social and environmental break-even point that every company must reach.

For companies to be able to monitor their performance and prioritize where action is needed most, each goal is supported by both progress and supplementary indicators. The Break-Even Goals present the requirements of what every company should do.

Table 2. Future-Fit Break-Even Goals (Future-Fit Business Benchmark, 2017).

\begin{tabular}{|l|l|c|c|c|c|}
\hline Future-Fit & \multirow{2}{*}{$\begin{array}{l}\text { B...must reach these Break-Even Goals } \\
\text { Business... }\end{array}$} & & \multicolumn{3}{|c|}{ Where in the value web this applies } \\
\cline { 3 - 6 } & & Suppliers & Operations & \multicolumn{1}{c|}{ Products } & \multicolumn{1}{c|}{ Society } \\
\hline \multirow{3}{*}{$\begin{array}{l}\text { Fosters } \\
\text { Wellbeing }\end{array}$} & Community health is safeguarded & 1 & $\mathrm{x}$ & & \\
\cline { 2 - 6 } & Employee health is safeguarded & 1 & $\mathrm{x}$ & & \\
\cline { 2 - 6 } & Employees are paid at least a living wage & 1 & $\mathrm{x}$ & & \\
\cline { 2 - 6 } & Employees are subject to fair employment terms & 1 & $\mathrm{x}$ & \\
\hline
\end{tabular}




\begin{tabular}{|c|c|c|c|c|c|}
\hline & Employees are not subject to discrimination & 1 & $x$ & & \\
\hline & $\begin{array}{l}\text { Employee concerns are actively solicited, impartially } \\
\text { judged and transparently addressed }\end{array}$ & 1 & $\mathrm{x}$ & & \\
\hline & $\begin{array}{l}\text { Product communications are honest, ethical, and } \\
\text { promote responsible use }\end{array}$ & & & $x$ & \\
\hline & Customer health is safeguarded & & & $x$ & \\
\hline & Products do not harm people or the environment & & & $\mathrm{x}$ & \\
\hline \multirow{7}{*}{$\begin{array}{l}\text { Respects } \\
\text { Nature }\end{array}$} & Energy comes from renewable sources & 1 & $x$ & & \\
\hline & $\begin{array}{l}\text { Water use is environmentally responsible and socially } \\
\text { equitable }\end{array}$ & 1 & $\mathrm{x}$ & & \\
\hline & $\begin{array}{l}\text { Natural resources are managed to respect the } \\
\text { wellfare of ecosystems, people and animals }\end{array}$ & 1 & $x$ & & \\
\hline & $\begin{array}{l}\text { Operational emissions do not harm people or the } \\
\text { environment }\end{array}$ & 1 & $\mathrm{x}$ & & \\
\hline & Operations emit no greenhouse gases & 1 & $x$ & & \\
\hline & $\begin{array}{l}\text { Operations do not encroach on ecosystems or } \\
\text { communities }\end{array}$ & 1 & $x$ & & \\
\hline & Products emit no greenhouse gases & & & $\mathrm{x}$ & \\
\hline \multirow{2}{*}{$\begin{array}{l}\text { Optimizes } \\
\text { Resources }\end{array}$} & Operational waste is eliminated & 1 & $x$ & & \\
\hline & Products can be repurposed & & & $x$ & \\
\hline \multirow{5}{*}{$\begin{array}{l}\text { Strengthens } \\
\text { Society }\end{array}$} & Procurement safeguards the pursuit of future-fitness & 1 & $\mathrm{x}$ & & \\
\hline & Business is conducted ethically & & & & $x$ \\
\hline & The right tax is paid in the right place at the right time & & & & $\mathrm{x}$ \\
\hline & $\begin{array}{l}\text { Lobbying and corporate influence safeguard the } \\
\text { pursuit of future-fitness }\end{array}$ & & & & $\mathrm{x}$ \\
\hline & Financial assets safeguard the pursuit of future-fitness & & & & $x$ \\
\hline
\end{tabular}

In addition to the Break-Even Goals, the FFBB includes instructions for positive pursuits of what any company may do. The positive pursuits mean actions a company takes to enable others in the value web to reach the break-even point (Future-Fit Business Benchmark, 2017). However, we concentrate only on the Break-Even Goals, and the positive pursuits are excluded from our framework (Figure 7). 


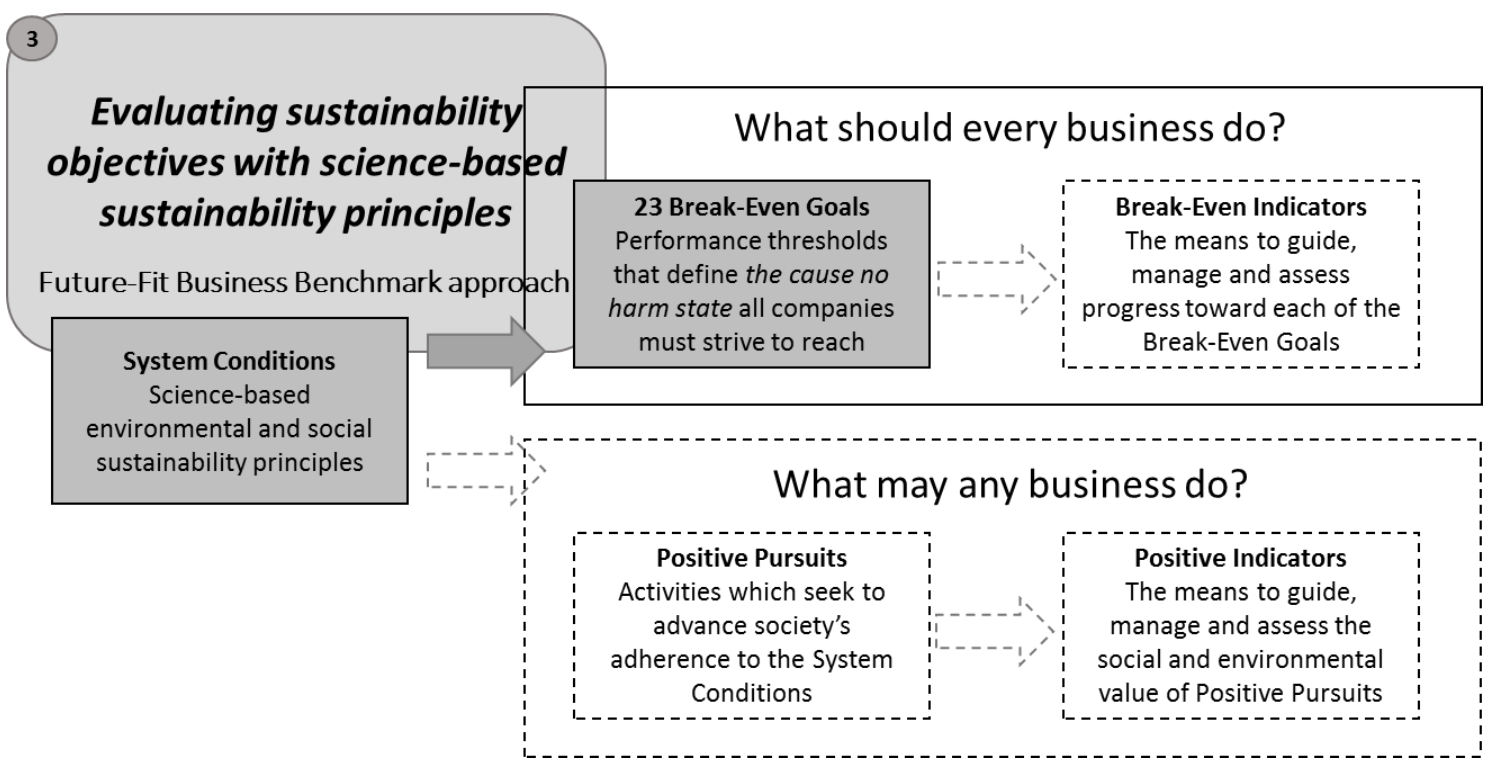

Figure 7. The connection of Future-Fit Business Benchmark (adapted from Future-Fit Foundation, 2017) and the ValuesDriven Sustainability Management Framework. The System Conditions and 23 Break-Even Goals are used as a basis to correlate sustainability objectives with science-based sustainability principles. The phases of the FFBB with dotted lines are excluded from the study.

\subsection{Reconsidering the values and resetting sustainability objectives}

In the fourth phase of the framework, no specific approach is utilized. At this phase, the decision makers are aware of their values on the one hand and scientific sustainability principles on the other, and can reconsider their values and possibly reset the sustainability objectives. The overall aim is that when decision makers go through all the phases of the framework, the values-based sustainability objectives are made transparent and the decision makers can recognize the gap between their objectives and the requirements of the sustainable development principles operationalized in the FFBB. The VFT approach has probably given some material to consider valuesbased alternatives to fill this gap. Recognizing the gap and analyzing their values helps decision makers to determine the sustainability strategy of the company and to form a basis for values-based sustainability goal setting that will truly foster sustainable development.

\section{Discussion and conclusion}

In this chapter, we have argued that strategic sustainability decision making requires understanding both the values of decision makers and facts from sustainability science. The values form the basis for the normative level of sustainability management, and sustainability science offers facts for setting the sustainability strategy. We have presented a framework of VDSM that combines these perspectives. The presented framework enables companies to rethink the purpose of doing business, as well as the way to do business. In addition, it provides phases which help decision makers to analyze their values and sustainability objectives in order to set values-based sustainability goals that comply with sustainability principles, thus truly fostering sustainable development. In the following sections, we present a few viewpoints of the framework in sustainability goal setting, and how the use of the framework supports operational sustainability management.

\subsection{Implications on sustainability goal setting}

The values of decision makers and facts from sustainability science provide a basis for a company's sustainability strategy, but the company still needs to make the strategy visible by determining longterm goals. The goals are related to the objectives firms want to reach, and concretize and make the 
objectives measurable. The goals are either achieved or not, and they can motivate for greater achievement of objectives. (Keeney, 1992.) The framework can be utilized in sustainability goal setting in the following ways.

Firstly, when the values are made transparent and the fundamental objectives are identified, there is a possibility that the analysis reveals something that the decision makers did not expect. It may seem, for example, that with the current identity and management philosophy, it is impossible to reach the goals proposed by the $\mathrm{FFBB}$, although the decision makers would be willing to try that. According to Lankoski and Smith (2017), it is a decision issue, how the decision makers want to conceive the relationship between two variables (in this case profit and sustainability). Therefore, they can choose to restructure their objective network, so that the emphasis on sustainability will increase and thus the FFBB goals will be more likely to be achieved.

Secondly, the framework helps companies to extend their outlook on the strategic objectives. One aim of the VFT approach is that it helps to create alternatives and to identify decision opportunities. Therefore, the decision makers can find new ways to influence sustainable development and rethink their objectives. In addition, a company may find out that a certain sustainability objective actually has an effect on some more fundamental objective or on a larger context. In this case, the role of sustainability goals is more instrumental and a means to achieve something else, but that else can be also other than profit.

Thirdly, the scientific perspective of sustainability helps companies to focus on essential issues and avoid greenwashing. When the values and science are combined, the decision makers can focus on those sustainability issues that are most important for them. This will increase their motivation, and the focus area can be later enlarged to involve other sustainability aspects as well.

Finally, the time perspective is emphasized when setting sustainability goals. For example, the realization of the 23 Break-Even Goals of the FFBB is a several years' process for many companies. In addition, a company that wants to act in a sustainable manner, and in the best case has a strong sustainability-dominant profile (Figure 4), needs profit to survive (Kanter, 2011, Stubbs and Cocklin, 2008). This means that a company probably cannot comply with the philosophy behind the sustainability-dominant profile in the short-term decisions every time. Although the ecocentric worldview is the overall management philosophy, decision makers are sometimes forced to make decisions where the instrumental role of sustainability is emphasized in order to ensure the company's future survival through profit making. Therefore, future research is needed to find out how a company with a sustainability-dominant profile can put its sustainability strategy into practice and solve the possible contradictions between profit and sustainability logics in decision making.

\subsection{Implications on the operational level of sustainability management}

When looking at the operational level of sustainability management, the research on sustainable business models has increased in recent years. However, a major barrier to sustainable business model innovation and design is the lack of a structuring systems perspective that includes an operational definition of sustainability and strategic guidelines for how an organization can support the sustainable development of the society while strengthening its own competitiveness (França et al., 2017). The comprehensive FSSD offers a process for strategic planning and includes sustainability principles. However, the framework of the FFBB can facilitate companies to set more concrete sustainability goals, because the FFBB gives a clear required state towards all companies must strive (Kurucz et al., 2017). In addition, when the values of decision makers are taken into account, there is greater possibility that the goals are tried to be reached. In other words, the idea of sustainable management is already included deeply in the normative management level (Baumgartner, 2014). In 
the best case, this will increase the innovations and the development of new sustainable business models, because new alternatives to reach the goals must be invented. 


\section{Reference}

Alencar, M.H., Priori Jr., L. and Alencar, L.H., 2017. Structuring objectives based on value-focused thinking methodology: Creating alternatives for sustainability in the built environment. Journal of Cleaner Production. 62-73.

Bansal, P. and Song, H., 2017. Similar but Not the Same: Differentiating Corporate Sustainability from Corporate Responsibility. Academy of Management Annals. 11, 105-149.

Baumgartner, R.J., 2014. Managing Corporate Sustainability and CSR: A Conceptual Framework Combining Values, Strategies and Instruments Contributing to Sustainable Development. Corporate Social Responsibility and Environmental Management. 21, 258-271.

Baumgartner, R.J., 2011. Critical perspectives of sustainable development research and practice. Journal of Cleaner Production. 19, 783-786.

Bertels, S. and Dobson, R., 2017. The Road to Context: Contextualising your

Strategy and Goals. A Guide. Embedding Project.

Broman, G.I. and Robèrt, K., 2017. A framework for strategic sustainable development. Journal of Cleaner Production. 140, 17-31.

Broman, G., Robèrt, K., Basile, G., Byggeth, S., Connell, T., Cook, D., Haraldsson, H., Johansson, L., MacDonald, J., Missimer, M., Ny, H., Oldmark, J., Moore, B. and Waldron, D., 2012. Sustainability Handbook. Planning Strategically towards Sustainability. Studentlitteratur AB, Lund.

den Ouden, E., 2012. Innovation Design: Creating Value for People, Organizations and Society. Springer London, London.

Dyllick, T. and Muff, K., 2016. Clarifying the Meaning of Sustainable Business. Organization \& Environment. 29, 156-174.

França, C.L., Broman, G., Robèrt, K., Basile, G. and Trygg, L., 2017. An approach to business model innovation and design for strategic sustainable development. Journal of Cleaner Production. 140, $155-166$.

Future-Fit Business Benchmark, 2017. Future-Fit Business Benchmark. Methodology Guide. Release 2.

Future-Fit Foundation, 2017. Future-Fit Business Benchmark. Request for Comments. Changes and additions proposed for Release 2.

Gao, J. and Bansal, P., 2013. Instrumental and Integrative Logics in Business Sustainability. Journal of Business Ethics. 112, 241-255.

Glynn, M.A., Lockwood, C., Raffaelli, R., 2015. Staying the Same While Changing: Organizational Identity in the Face of Environmental Challenges, in: Henderson, R., Gulati, R., Tushman, M. (Eds.). Leading Sustainable Change: An Organizational Perspective. Oxford University Press, pp. 143-170.

Greenwood, R., Devereaux Jennings, P., Hining, B., 2015. Sustainability and Organizational Change: An Institutional Perspective, in: Henderson, R., Gulati, R., Tushman, M. (Eds.). Leading Sustainable Change - An Organizational Perspective. pp. 323-355. 
Henderson, R., Gulati, R., Tushman, M., 2015. Leading\&nbsp; Sustainable Change - An Introduction, in: Henderson, R., Gulati, R., Tushman, M. (Eds.). Leading Sustainable Change - An Organizational Perspective. pp. 3-21.

Henderson, R. and Van den Steen, E., 2015. Why Do Firms Have "Purpose"? The Firm's Role as a Carrier of Identity and Reputation. American Economic Review. 105, 326-330.

Kaldschmidt, S., 2011. The Values of Sustainability: The Influence of Leaders' Personal Values on Sustainability Strategies.

Kanter, R.M., 2011. How Great Companies Think Differently. Harvard Business Review. 89, 66-78.

Keeney, R.L., 1996. Value-focused thinking: Identifying decision opportunities and creating alternatives. European Journal of Operational Research. 92, 537-549.

Keeney, R.L., 1994. Using Values in Operations Research. Operations Research. 42, 793-813.

Keeney, R.L., 1992. Value-Focused Thinking: A Path to Creative Decisionmaking. Harvard University Press, Cambridge (MA).

Kurucz, E.C., Colbert, B.A., Lüdeke-Freund, F., Upward, A. and Willard, B., 2017. Relational leadership for strategic sustainability: practices and capabilities to advance the design and assessment of sustainable business models. Journal of Cleaner Production. 140, 189-204.

Landrum, N.E. and Ohsowski, B., 2017. Identifying Worldviews on Corporate Sustainability: A Content Analysis of Corporate Sustainability Reports. Business Strategy and the Environment.

Lankoski, L. and Smith, N.C., 2017. Alternative Objective Functions for Firms. Organization \& Environment. 1-21.

Markman, G.D., Russo, M., Lumpkin, G.T., Jennings, P.D.D. and Mair, J., 2016. Entrepreneurship as a Platform for Pursuing Multiple Goals: A Special Issue on Sustainability, Ethics, and Entrepreneurship. Journal of Management Studies. 53, 673-694.

Montabon, F., Pagell, M. and Wu, Z., 2016. Making Sustainability Sustainable. Journal of Supply Chain Management. 52, 11-27.

O'Neill, R. and McElroy, S., 2017. Targeting Value: Setting, Tracking \&amp; Integrating High-Impact Sustainability Goals. SustainAbility.

Palmer, T.B. and Flanagan, D.J., 2016. The sustainable company: looking at goals for people, planet and profits. Journal of Business Strategy. 37, 28-38.

Pearce, J.A., 2013. Using Social Identity Theory to Predict Managers' Emphases on Ethical and Legal Values in Judging Business Issues. Journal of Business Ethics. 112, 497-514.

Purser, R.E., Park, C. and Montuori, A., 1995. Limits to Anthropocentrism: Toward an Ecocentric Organization Paradigm? The Academy of Management Review. 20, 1053-1089.

Schaltegger, S. and Hörisch, J., 2017. In Search of the Dominant Rationale in Sustainability Management: Legitimacy- or Profit-Seeking? Journal of Business Ethics. 145, 259-276.

Schwartz, S., 2006. A Theory of Cultural Value Orientations: Explication and Applications. Comparative Sociology. 5, 137-182. 
Schwartz, S.H., 2007. Value Orientations: Measurement, Antecedents and Consequences Across Nations, in: Measuring Attitudes Cross-Nationally: Lessons from the European Social Survey. SAGE Publications, Ltd, London.

Schwartz, S.H., 1992. Universals in the Content and Structure of Values: Theoretical Advances and Empirical Tests in 20 Countries, in: Advances in Experimental Social Psychology. Elsevier Science \& Technology, pp. 1-65.

Schwartz, S.H. and Bilsky, W., 1987. Toward A Universal Psychological Structure of Human Values. Journal of Personality and Social Psychology. 53, 550-562.

Science Based Targets, 2018. Science Based Targets. http://sciencebasedtargets.org/contact-us/. Accessed February 12, 2018.

Silvestri, L. and Gulati, R., 2015. From Periphery to Core: A Process Model from Embracing Sustainability, in: Henderson, R., Gulati, R. (Eds.). Leading Sustainable Change: An Organizational Perspective. Oxford University Press, pp. 81-110.

Starik, M. and Kanashiro, P., 2013. Toward a Theory of Sustainability Management: Uncovering and Integrating the Nearly Obvious. Organization \& Environment. 26, 7-30.

Stubbs, W. and Cocklin, C., 2008. Conceptualizing a "Sustainability Business Model". Organization \& Environment. 21, 103-127.

Whiteman, G., Walker, B. and Perego, P., 2013. Planetary Boundaries: Ecological Foundations for Corporate Sustainability. Journal of Management Studies. 50, 307-336. 